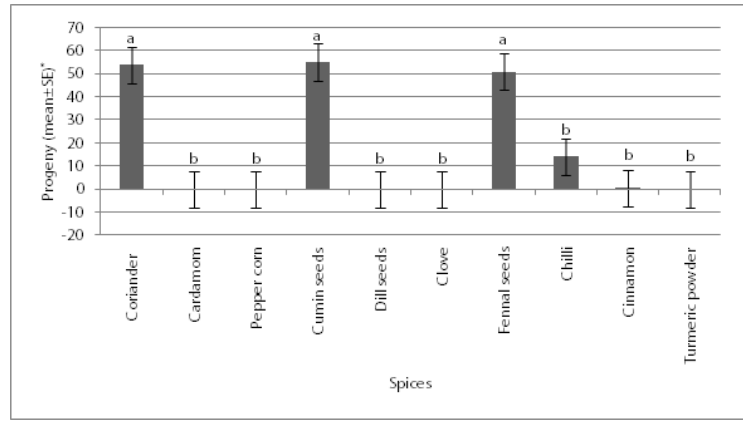

*Progeny produced in spices followed by the same letter are not significantly different according to Tukey's test.

Fig. 2 Progeny adults emerged (mean \pm SE) in different spices two months following initial infestation.

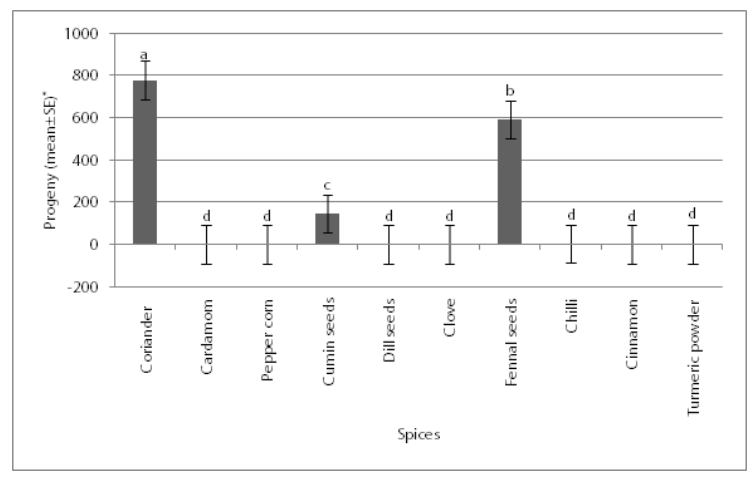

*Progeny produced in spices followed by the same letter are not significantly different according to Tukey's test.

Fig. 3 Progeny adults emerged (mean \pm SE) in different spices three months following initial infestation.

\title{
References
}

CABRERA, B. J. 2014. Drugstore Beetle, Stegobium paniceum (L.) (Insecta: Coleoptera:Anobiidae). (https://edis.ifas.ufl.edu/pdffiles/IN/IN38500.pdf) Accessed March 20, 2018.

WIJAYARATNE, L.K.W., ARTHUR, F.H., WHYARD, S. 2018. Methoprene and control of stored-product insects. Journal of Stored Products Research 76, 161-169.

\section{The developmental parameters of the minute brown scavenger beetle Dienerella argus (Coleoptera: Latridiidae)}

\section{Toshihiro Imai}

Leaf Tobacco Research Center, Japan Tobacco Inc., Oyama, Tochigi 323-0808, Japan

E-mail: toshihiro.imai@jt.com

DOI 10.5073/jka.2018.463.048

\section{Abstract}

Adults and larvae of Dienerella argus (Reitter) (Coleoptera: Latridiidae) feed on fungi and are frequently found in indoor, moldy areas. The basic biology of this species, other than its feeding habits, has not been determined. In this study, the developmental parameters of the beetle were investigated using dried hyphae and conidia from three fungi that are common in living areas. The developmental periods of the beetle on Cladosporium cladosporioides, Penicillium citrinum, and $P$. decumbens were examined at $16,20,24,28,32^{\circ} \mathrm{C} / 70-75 \% \mathrm{RH}$ under dark conditions. The low developmental threshold temperatures and thermal constants calculated from egg to adult emergence were $10.5^{\circ} \mathrm{C}$ and $526 \mathrm{DD}$ (degree day), $9.0^{\circ} \mathrm{C}$ and $500 \mathrm{DD}$, and $10.9^{\circ} \mathrm{C}$ and $370 \mathrm{DD}$ on $\mathrm{C}$. 
cladosporioides, $P$. citrinum, and $P$. decumbens, respectively. These developmental parameters indicate that these beetles can breed year-round in indoor areas that are in air-conditioned facilities.

Keywords: Dienerella argus, developmental period, low developmental threshold temperature, thermal constant, Cladosporium, Penicillium

\section{Introduction}

Latridiidae is a family of small (1-3 mm) mycophagous beetles that includes 761 species according to Rücker (2015). These beetles are named minute brown scavenger beetles, or plaster beetles for some indoor species, and are found in moldy areas, on debris and occasionally on flowers. At least 30 species have been listed as stored product pests, although they do not directly affect stored foods but feed entirely on the fungi that grow on foods (Hinton 1941). Most species associated with stored foods are dispersed worldwide, perhaps due to the international transportation of food commodities. Dienerella argus (Reitter) is one of these wide-ranging species that was introduced into Japan (Mito and Uesugi 2004). Stored-product pest species usually adapt to indoor environments and are frequently found in moldy areas such as plaster walls in a damp-dried state; under floors, garrets, and internal wall structures; and in air-conditioning and refrigeration systems, where dew condensation occurs, as well as hospitals or sterile drug processing areas (Carlton 1988; Robinson 2005; Tanaka 1986; Tani and Ito 2006). In manufacturing industries, the populations of these beetles sometimes increase explosively inside factories or warehouses, causing insect contamination in products. These beetles may possibly cause sanitary problems by spreading fungus spores (Robinson 2005). For example, Tani and Ito (2006) isolated the fungi Cladosporium spp. and Penicillium spp. from the body surface of Dienerella costulata (Reitter) and three fungus genera including Aspergillus from another latridiid beetle. Currently, little is known about the basic biology of these species, except for feeding habits. Since a successful artificial rearing method has been established for the beetles using dried hyphae and conidia of fungi, the low developmental threshold temperature and thermal constant of the beetle on three fungi, Cladosporium cladosporioides, Penicillium citrinum, and $P$. decumbens, were examined.

\section{Materials and Methods}

\section{2-1. Collection and rearing method of Dienerella argus}

Adult beetles were collected from the floor using a vacuum cleaner at a laboratory in the Manufacturing Technology Center, Japan Tobacco Inc. (Tokyo), where an outbreak of this insect had occurred. The insects were preserved on the dried hyphae and conidia of Cladosporium cladosporioides (NBRC6348) on potato dextrose agar (PDA). Approximately 30 adults that were 1-4 weeks old were placed on dried fungi in a petri dish and kept under $27^{\circ} \mathrm{C}, 75 \% \mathrm{RH}$ and dark conditions. The adults were removed after two weeks. The next generation adults emerged after one month under these conditions.

\section{2-2. Fungi}

C. cladosporioides (NBRC6348) and P. citrinum (NBRC 6352) were obtained from the Biological Resource Center, National Institute of Technology and Evaluation, Chiba, Japan. P. decumbens was collected from above the ceiling of the laboratory where $D$. argus was collected. An open plate method was used in which the airborne particles were passively collected and preserved on PDA in a petri dish that was uncovered for $30 \mathrm{~min}$. Then, the Petri dishes were kept under $25^{\circ} \mathrm{C}$, and fungal colonies were isolated. The primary culture and subculture of these fungi were prepared on PDA in 90-mm plastic Petri dishes for $3-6$ weeks at $25^{\circ} \mathrm{C}$. Spore-formed cultures were dried under room conditions $\left(23-28^{\circ} \mathrm{C}\right.$ and $\left.40-70 \% \mathrm{RH}\right)$ and provided to the insects. 


\section{2-3. Developmental parameters}

The developmental periods from egg to adult were examined on the three fungi $C$. cladosporioides, $P$. citrinum, and $P$. decumbens. Ten mating pairs were placed on the dried fungi in the Petri dishes. The Petri dishes were enclosed in $11.5 \mathrm{~cm} \times 19.5 \mathrm{~cm} \times 7.0 \mathrm{~cm}$ plastic containers with saturated $\mathrm{NaCl}$ solution in a $2.5 \mathrm{~cm} \phi \times 5 \mathrm{~cm}$ cup to maintain humidity at $70-75 \% \mathrm{RH}$ and kept in a $28^{\circ} \mathrm{C}$ chamber. After 16-20 h, the adults were removed and the containers were transferred to chambers set at 16 , $20,24,28,32{ }^{\circ} \mathrm{C}$ under dark conditions. Two replications were carried out for each fungus and temperature. Actual temperatures in the containers were recorded at one hour intervals by the thermo recorder. Adult emergence was checked at 1-3 d intervals. The timing of eclosion was assumed to occur during the observation intervals that were in the middle of the study period. The low developmental threshold temperature $\left(T_{0}\right)$ and thermal constant $(K)$ were obtained from the regression lines of $1 / D$ against $T$, where $D$ is the developmental period in days from egg to adult, and $T$ is temperature in ${ }^{\circ} \mathrm{C}$ (Kiritani 2012).

\section{Results}

Egg to adult development occurred for all fungi tested, and the adults that emerged were both viable and fertile. Table 1 shows the developmental periods under different temperature conditions, and the values of $T_{0}$ and $K$ calculated for the three fungi. Development periods were slightly different among the fungi. The period was delayed by one week to ten days for complete growth on $C$. cladosporioides compared to the periods for Penicillium spp.

Tab. 1 Developmental periods at five temperatures and developmental parameters for Dienerella argus on three fungi.

\begin{tabular}{llll}
\hline \multirow{2}{*}{ Temperature, ${ }^{\circ} \mathrm{C}$} & \multicolumn{3}{l}{ Developmental period in days, mean \pm SD (Number of adults emerged) } \\
\cline { 2 - 4 } & Cladosporium cladosporioides & Penicillium citrinum & Penicillium decumbens \\
\hline 15.4 & $95.5 \pm 4.3$ & $85.0 \pm 5.1$ & $88.4 \pm 3.0$ \\
19.4 & $54.2 \pm 2.5$ & $46.0 \pm 3.7$ & $45.8 \pm 3.1$ \\
23.3 & $40.3 \pm 2.6$ & $31.3 \pm 0.8$ & $29.3 \pm 0.8$ \\
27.3 & $31.5 \pm 8.5$ & $26.8 \pm 2.9$ & $21.1 \pm 2.3$ \\
31.7 & $25.4 \pm 3.9$ & $22.2 \pm 3.1$ & $18.9 \pm 0.4$ \\
\hline Low developmental & $10.5^{\circ} \mathrm{C}$ & $9.0^{\circ} \mathrm{C}$ & $10.9{ }^{\circ} \mathrm{C}$ \\
threshold & $526 \mathrm{DD}$ & $500 \mathrm{DD}$ & $370 \mathrm{DD}$ \\
Thermal constant & & & \\
\hline
\end{tabular}

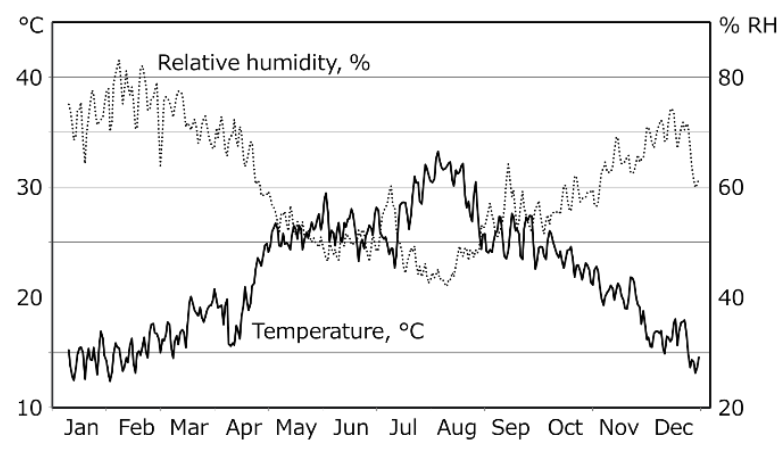

Fig. 1 Temperature and humidity above the ceiling panel of the laboratory where the outbreak of Dienerella argus occurred. Solid and dotted lines represent daily mean temperature and relative humidity, respectively. 


\section{Discussion}

Although the developmental parameters for Latridiid beetles have not been elucidated, Hinton (1941) described the life histories of several species on cultures of Penicillium glaucum and Mucor mucedo on bread and cheese. The durations of the time the egg was laid to adult emergence were 27-32 d (egg to the second instar larval stage was at $15.6^{\circ} \mathrm{C}$ and the third instar to pupal stage was at $20^{\circ} \mathrm{C}$ ) for Cartodere nodifer (Westwood), $36 \mathrm{~d}$ at $23.9^{\circ} \mathrm{C}$ for Dienerella filum (Aubé), $51-52 \mathrm{~d}$ (egg at $17.2^{\circ} \mathrm{C}$ and larva to pupa at $19.4{ }^{\circ} \mathrm{C}$ ) for $D$. filiformis (Gyllenhal), and $40 \mathrm{~d}$ at $18.3^{\circ} \mathrm{C}$ for Corticaria fulva (Comolli) (Hinton 1941). The period from egg to adult observed for D. argus in the present study was longer than the periods observed for Cartodere nodifer and Corticaria fulva, and was the same as the periods observed for the two Dienerella species at comparable temperatures. Based on the systematic review by Kiritani (2012), the average $T_{0}$ and $K$ values from egg to adult for 31 coleopteran species are $10.9 \pm 2.5^{\circ} \mathrm{C}$ and $415 \pm 239 \mathrm{DD}$ (mean $\pm \mathrm{SD}$ ), respectively. The $T_{0}$ and $K$ values for $D$. argus were $10.5^{\circ} \mathrm{C}$ and $526 \mathrm{DD}$ on C. cladosporioides, $9.0^{\circ} \mathrm{C}$ and $500 \mathrm{DD}$ on $P$. citrinum, and $10.9^{\circ} \mathrm{C}$ and $370 \mathrm{DD}$ on $P$. decumbens, all of which are average values for coleopterans.

The daily mean temperatures of the garret of the laboratory, the original location of the test insects, fluctuated within the range of $12-17^{\circ} \mathrm{C}$ in the winter, constantly surpassing $T_{0}\left(=9.0-10.9^{\circ} \mathrm{C}\right)$ (Fig. 1). This result strongly suggests that $D$. argus had bred there year-round. In fact, the adult beetles were caught irrespective of the season. Because the female adults require at least one week before starting oviposition at $25-30{ }^{\circ} \mathrm{C}$, the thermal constant $K$ for one generation on $P$. decumbens was assumed to be 470-500 DD (370 DD for egg to adult emergence $+100-130$ DD for the preoviposition period). The accumulated daily mean temperature above $10.9^{\circ} \mathrm{C}$ was calculated at 3974 $\mathrm{DD}$ in the garret of laboratory, and the number of generations per year was estimated at eight.

\section{Acknowledgement}

The author thanks Dr. Yoko Miyamoto of the Leaf Tobacco Research Center, Japan Tobacco Inc. for the identification of fungi. We also thank Mr. Eisuke Taniguchi of the Manufacturing Technology Center, Japan Tobacco Inc. for his helpful support during field investigations.

\section{References}

Carlton, C. E., 1988: Dienerella filum (Aubé) (Coleoptera: Lathridiidae), a potential pest of air conditioning systems. The Coleopterists Bulletin 42, 263-264.

Hinton, H. E., 1941: The lathridiidae of economic importance. Bulletin of Entomological Research 32, 191-247.

Kiritani, K., 2012: The low development threshold temperature and the thermal constant in insects and mites in Japan (2nd edition). Bulletin of National Institute for Agro-Environmental Sciences 31, 1-74. (in Japanese with English summary)

Mito, T. und T. Uesugi, 2004: Invasive alien species in Japan: The status quo and the new regulation for prevention of their adverse effects. Global Environmental Research 8, 171-191.

Robinson, W. H., 2005: Coleoptera. In: Urban insects and arachnids. Cambridge University Press, Cambridge, pp 65-138.

Rücker, H. W. H., 2015: Checklist Latridiidae \& Merophysiidae of the World Ausgabe 2015. http://www.latridiidae.de/downloads2015.htm. Accessed 30 January 2018

Tanaka, K., 1986: On house-infecting species of the lathridiidae from Japan (Coleoptera). House and Household Insect Pests 27/28, 41-54. (in Japanese)

Tani, T und T. Ito, 2006: Arthropods in APAs: Their distribution and cause of infestation. PDA Journal of GMP and Validation in Japan 8, 68-77. (in Japanese with English summary)

\section{Comparison of mandible morphology of two stored product bostrichid beetles, Rhyzopertha dominica and Prostephanus truncatus}

\section{Tomas VendI*, Radek Aulicky, Vaclav Stejskal}

Crop Research Institute, Drnovska 507, 161 06, Prague, Czech Republic

*Corresponding author: vendl.tomas@gmail.com

DOI 10.5073/jka.2018.463.049 